Polymer Journal, Vol. 8, No. 1, pp 35-42 (1976)

\title{
Differential Thermal Analysis of Polytetraoxane Obtained by Radiation-Induced Polymerization in the Solid State. II. Effect of Various Atmospheres during Annealing
}

\author{
Yoshiaki NAKASE and Isamu KuriYAmA \\ Takasaki Radiation Chemistry Research Establishment, Japan Atomic \\ Energy Research Institute, Takasaki, Japan.
}

Akira Odajima

Department of Applied Physics, Faculty of Engineering, Hokkaido University, Sapporo, Japan.

(Received May 19, 1975)

\begin{abstract}
Differential thermal analysis was carried out on polytetraoxane obtained by radiation-induced polymerization of tetraoxane in the solid state and on the sample annealed under various atmospheres.

Annealing under an oxygen atmosphere causes degradation of the polymer chains especially in the molten phase. The annealing in a closed ampule gives a similar result to annealing under a nitrogen stream, while annealing in an open ampule is similar to that under an oxygen stream.

In the annealing at a temperature below the starting temperature of melting $\left(T_{\mathrm{s}}\right)$ of the melt-crystallized poly(oxymethylene) of acetylated polytrioxane (Delrin like), rearrangement of the chains takes place to give a sharp melting endotherm on the heating curve, while in the annealing above $T_{\mathrm{s}}$, a similar profile of the melting endotherm to that of the melt-crystallized material is obtained. In the case of polytetraoxane, the annealing above $T_{\mathrm{s}}$, as well as below $T_{\mathrm{s}}$, causes the rearrangement indicating the difference in the microstructure from the melt-crystallized form.

When the double melting endothermic peaks are observed in the sample annealed, discrete scattering is found in the meridional direction of the SAXS pattern, indicating the overgrowth of the folded chain crystal (shish-kebab type) from the partial melt.

KEY WORDS Polytetraoxane / Annealing Atmosphere / Differential Thermal Analysis / Small-Angle X-Ray Scattering / Partial Melt / Overgrowth / Shish-Kebab Type /
\end{abstract}

It was reported that degradation of the polymer during the radiation-induced polymerization of tetraoxane in the solid state was observed in the presence of oxygen or air, ${ }^{1}$ and that destruction of the polymer crystal occurred in view of the melting behavior. ${ }^{2}$ It was also suggested that the structure of the original polymer crystal was of the extended chain type, that the crystal rearranged easily during heating, and that the crystal newly formed in the annealing above $170^{\circ} \mathrm{C}$ had the folded chain structure.

It is well-known that poly(oxymethylene) has very low thermal stability, probably due to its ease of oxidation on heating.
In this paper, the effect of various atmospheres during annealing on the micro (fine) structure of the polymer crystal is investigated in detail mainly using a differential scanning calorimeter (DSC). Moreover, it is proved that partial melting occurs during annealing and then a lamellar crystal forms on cooling from the annealing temperature. The structure of the polymer crystal is also discussed using $\mathrm{X}$-ray wideand small-angles scattering patterns.

\section{EXPERIMENTAL}

Tetraoxane crystal (ca. $1 \mathrm{~mm} \phi \times 10 \mathrm{~mm}$ ) was 
prepared by sublimation under reduced pressure and polymerized by $\gamma$-ray induced postpolymerization in the solid state in air. The polymerization condition was described in detail elsewhere. ${ }^{1}$

Polytetraoxane prepared maintained the appearance of the same needle-shaped structure with the monomeric tetraoxane crystal.

The samples, polytetraoxane crystal, were annealed both in a metal oven, the temperature of which was controlled to an accuracy better than $\pm 0.1^{\circ} \mathrm{C}$, and in an apparatus used for the measurement of melting behavior. The annealing of the sample was performed under a nitrogen or an oxygen atmosphere. After a given annealing time at a desired temperature, the sample was taken out of the oven at room temperature, and in the case of annealing in the apparatus, the sample was cooled to about $100^{\circ} \mathrm{C}$ at a controlled rate $\left(64^{\circ} \mathrm{C} / \mathrm{min}\right)$.

The apparatus for the measurement of the melting behavior of polymer was a differential scanning calorimeter (DSC-1B, Perkin-Elmer). A small amount of the sample (about $1 \mathrm{mg}$ ) was used. The heating rate used was $16^{\circ} \mathrm{C} / \mathrm{min}$ in most cases and the instrument was calibrated with indium as a standard.

The small-angle X-ray scattering patterns were obtained with a Rigaku Denki RU-3 rotating anode using a Pin-hole collimation system (0.5$0.3 \mathrm{~mm} \phi)$. The path of the scattered X-rays were evacuated to avoid air scattering. In all cases the copper radiation was nickel-filtered and operated at $40 \mathrm{kV}, 80 \mathrm{~mA}$. The axis of the needle-shaped polymers was normal to the $\mathrm{X}$ ray beam. The wide-angle $X$-ray measurements were also carried out with the same X-ray source using a flat plate camera for rotation patterns. The axis of the rotation was the long axis (cmolecular axis) of the sample.

\section{RESULTS AND DISCUSSION}

In the preceding paper, ${ }^{2}$ the annealing effect of polytetraoxane obtained in vacuum was investigated under a nitrogen atmosphere, and the profile of the melting endotherm was closely related to the polymer yield and the molecular weight of polymer obtained. The molecular weight of the polymer obtained in a nitrogen atmosphere is higher than that obtained in air. ${ }^{t}$ Thus the profile of melting endotherm and the annealing effect on the polymers obtained in air and in a nitrogen atmosphere may be not alike because of marked difference of the molecular weight.

Figure 1 shows the melting endotherm of the polymers (as-polymerized and annealed) obtained in air or in nitrogen. The polymer yield is chosen to be similar, while the molecular weight of polymer obtained in nitrogen is 5 times as large as that obtained in air. ${ }^{1}$ It is noticed that the original sample postpolymerized in air is harder to anneal than that postpolymerized in nitrogen (in the absence of oxygen) because of the sharper melting endotherm after annealing. However, the tendency to the fine structural change on annealing is quite similar in both cases, the postpolymerized in air or in nitrogen. Thus the rearrangement of the polymer chains occurs in the annealing at $170^{\circ} \mathrm{C}$ and a new

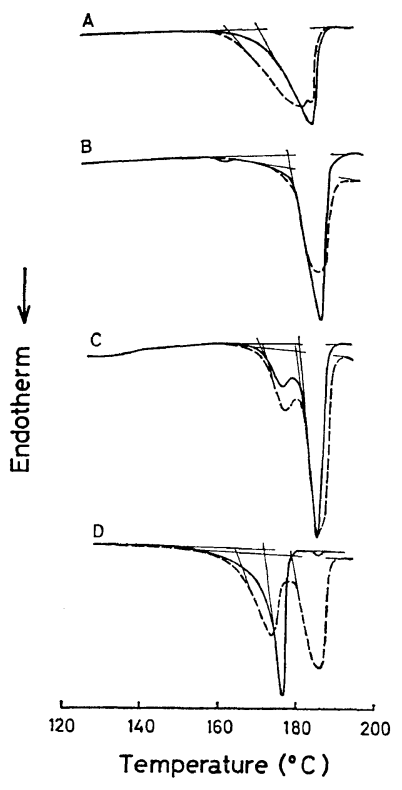

Figure 1. Melting endotherms of polytetraoxane obtained by radiation-induced postpolymerization in the solid state in air (---) or in a nitrogen $(\longrightarrow$ ) atmosphere: Polymer yield, $40 \%$; sample weight, $1.0 \pm 0.1 \mathrm{mg}$; heating rate, $16^{\circ} \mathrm{C} / \mathrm{min} ; \mathrm{A}$, original (as-polymerized); $\mathrm{B}$, annealed at $170^{\circ} \mathrm{C}$ for $10 \mathrm{~min}$; $\mathrm{C}$, annealed at $173^{\circ} \mathrm{C}$ for $10 \mathrm{~min}$; $\mathrm{D}$, annealed at $178^{\circ} \mathrm{C}$ for $5 \mathrm{~min}$. 
melting endotherm is observed at the lower temperature beside an endotherm at the higher temperature in the annealing above $170^{\circ} \mathrm{C}$.

The further experiment has been carried out with the polymer obtained in air in this paper in order to clarify the structural characteristics of the polymer.

It was suggested in the preceding paper ${ }^{2}$ that the structure giving an endotherm at a lower temperature in the heating curve was of the crystal formed from the partial melt. This suggestion is examined by the technique of heating the sample directly without cooling from the annealing temperature under various atmosphere.

Annealing in Nitrogen or Oxygen Atmosphere

Figure 2 shows the melting endotherm of the sample heated up from the annealing temperature of $170^{\circ} \mathrm{C}(\mathrm{C})$, and also heating curves of an original sample (A) and once cooled down to room temperature after annealing (B) for comparison. The area under the endothermic peak of the curve $\mathrm{C}$ coincides fairly well (in mcal $\mathrm{mg}^{-1}$ ) with that of the curve B. In the annealing at $170^{\circ} \mathrm{C}$, the rearrangement of the polymer chains occurs, but no partial melting is detectable.

Figure 3 shows the heating curves of the

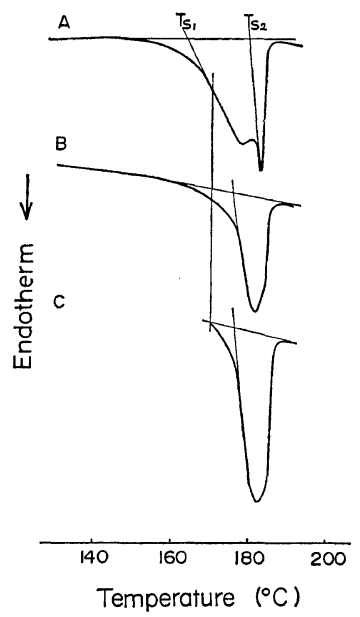

Figure 2. Melting endotherms of polytetraoxane annealed at $170^{\circ} \mathrm{C}$ for $10 \mathrm{~min}$ under a nitrogen atmosphere: Polymer yield, $40 \%$ (polymerized in air); heating rate, $16^{\circ} \mathrm{C} / \mathrm{min}$; $\mathrm{A}$, original (unannealed); $\mathrm{B}$, annealed and cooled to room temperature with the rate of $64^{\circ} \mathrm{C} / \mathrm{min} ; \mathrm{C}$, annealed and heated up from $170^{\circ} \mathrm{C}$.

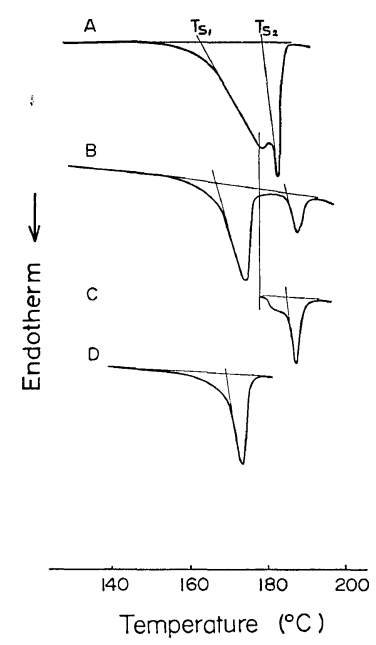

Figure 3. Melting endotherms of polytetraoxane annealed at $178^{\circ} \mathrm{C}$ for $10 \mathrm{~min}$ under a nitrogen atmosphere: Polymer yield, 40\% (polymerized in air); heating rate, $16^{\circ} \mathrm{C} / \mathrm{min}$; $\mathrm{A}$, original; $\mathrm{B}$, annealed and cooled to room temperature with the rate of $64^{\circ} \mathrm{C} / \mathrm{min} ; \mathrm{C}$, annealed and heated up from $178^{\circ} \mathrm{C} ; \mathrm{D}$, melt-crystallized from $195^{\circ} \mathrm{C}$.

sample annealed at $178^{\circ} \mathrm{C}$. The heating curve of the sample annealed for $10 \mathrm{~min}$ and heated up without cooling from $178^{\circ} \mathrm{C}(\mathrm{C})$ has a quite sharp, but weak, endothermic peak. The area under the peak of the curve $C$ nearly equals the area under the endothermic peak at the higher temperature of the heating curve $B$ of the sample cooled once to room temperature.

The melting endotherm at a lower temperature of the curve $B$ is exactly similar to that of the curve $\mathrm{D}$ of the sample cooled down to room temperature after complete melting. It is confirmed that the endotherm at lower temperature in the heating curve of the sample annealed above $170^{\circ} \mathrm{C}$ is of the crystal formed from the partially molten phase.

It is well-known that poly(oxymethylene) decomposes easily during the heating process in air, so the effect of oxygen during annealing was investigated.

Figure 4 shows the melting endotherms heated up without cooling from annealing temperature (B and D) and also the melting endotherms of the sample cooled once down to room temperature (A and $\mathrm{C}$ ). The endothermic peak observed in the heating curves of the samples $\mathbf{A}$ and $\mathbf{B}$ 


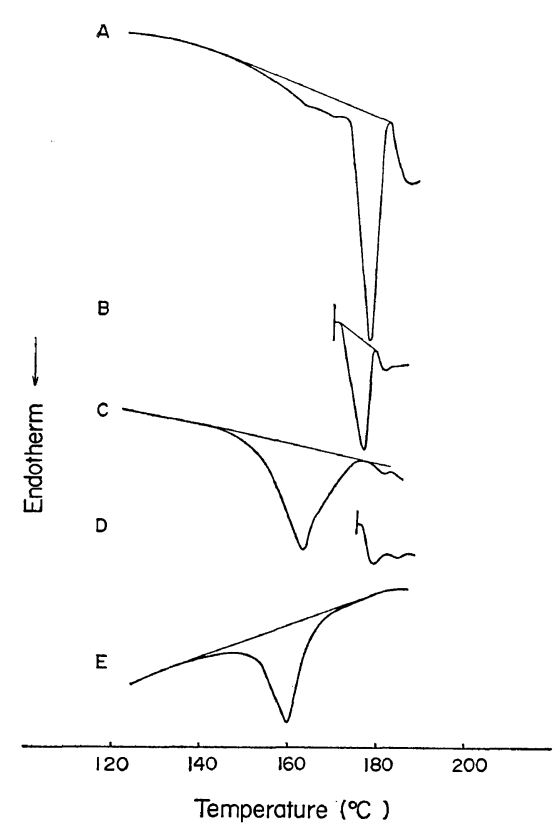

Figure 4. Melting endotherms of Polytetraoxane annealed under an oxygen atmosphere: Polymer yield, $40 \%$ (in air); heating rate, $16^{\circ} \mathrm{C} / \mathrm{min} ; \mathrm{A}$, annealed at $170^{\circ} \mathrm{C}$ for $10 \mathrm{~min}$ and cooled to room temperature with the cooling rate of $64^{\circ} \mathrm{C} / \mathrm{min}$; $B$, annealed and heated up from $170^{\circ} \mathrm{C} ; \mathrm{C}$, annealed at $176^{\circ} \mathrm{C}$ for $5 \mathrm{~min}$ and cooled to room temperature with $64^{\circ} \mathrm{C} / \mathrm{min} ; \mathrm{D}$, annealed and heated up from $176^{\circ} \mathrm{C}$; E, 2nd run of $\mathrm{C}$ (melt-crystallized).

is due to the melting of the crystal presented in the system during annealing. The heating curves of the samples $C$ and $D$ show that little of the crystal is left during annealing at $176^{\circ} \mathrm{C}$ for $5 \mathrm{~min}$ under an oxygen stream and that the profile of the melting endotherm of the heating curve $C$ is quite similar to that of the sample melt-crystallized (E), the second run of the heating curve $C$.

The comparison between Figures 3 and 4 suggests as follows: In the annealing at $170^{\circ} \mathrm{C}$, rearrangement of the polymer chains occurs both in a nitrogen and an oxygen atmosphere. In the annealing above $170^{\circ} \mathrm{C}$, namely at 176 or $178^{\circ} \mathrm{C}$, partial melting occurs to leave just the main crystals in the case of a nitrogen atmosphere. In the case of an oxygen atmosphere, main crystals are left during annealing, and the melting endotherm at the lower temperature is quite broad at sufficiently low temperatures indicating chain scission during annealing.

It is confirmed in the decomposition of poly(oxymethylene) that the degradation occurs easily when the sample is in the molten phase under an oxygen atmosphere.

Annealing under Nitrogen Atmosphere in Relation to $T_{\mathrm{s}}$

In the annealing of polytetraoxane at $170^{\circ} \mathrm{C}$, the rearrangement of the polymer chains occurs to give a single melting endotherm (Figure 2), while at $178^{\circ} \mathrm{C}$, the double melting endothermic peaks (Figure 3) are observed. Both temperature, 170 and $178^{\circ} \mathrm{C}$, are higher than the starting temperature of an endotherm $\left(T_{\mathrm{s}}\right)$ of the original sample as shown in Figures 2 and 3 . There must, therefore, be a preferential temperature for the annealing effect on the polytetraoxane as described in the preceding paper. ${ }^{2}$ The effect of an annealing temperature on the profile of the heating curve is, therefore, examined in relation to $T_{\mathrm{s}}$ with various types of polyoxymethylene.

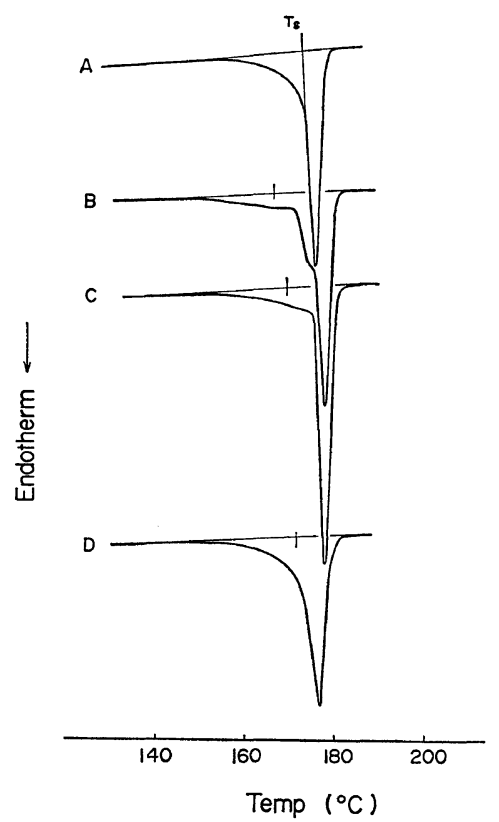

Figure 5. Melting endotherms of the melt-crystallized poly(oxymethylene), acetylated polytrioxane, annealed for $10 \mathrm{~min}$ at various temperatures under a nitrogen atmosphere: Heating rate, $16^{\circ} \mathrm{C} / \mathrm{min}$; A, original; $\mathrm{B}$, annealed at $165^{\circ} \mathrm{C}\left(T_{\mathrm{s}}-5.5\right) ; \mathrm{C}$, annealed at $168^{\circ} \mathrm{C}\left(T_{\mathrm{S}}-2.5\right) ; \mathrm{D}$, annealed at $171^{\circ} \mathrm{C}$ $\left(T_{\mathrm{s}}+0.5\right)$. 
a) Figure 5 shows the heating curves of the melt-crystallized polytrioxane, acetylated by acetic anhydride. ${ }^{3}$ In the annealing at a temperature below $T_{\mathrm{s}}\left(170.5^{\circ} \mathrm{C}\right)$, the rearrangement of the original polymer chain occurs to give a melting endotherm at a temperature (B and $\mathrm{C}$ ) higher than that of the original (A) while the annealing above $T_{\mathrm{s}}$ makes no special change in the melting endotherm (D) compared with that of the original (A).

b) A similar examination is performed with polytetraoxane annealed above $170^{\circ} \mathrm{C}$, where the heating curves show double endothermic peaks.

Figure 6 shows the heating curves of the sample annealed at $178^{\circ} \mathrm{C}$ for $5 \mathrm{~min}$ (A) and then annealed at $170^{\circ} \mathrm{C}$ for $30 \mathrm{~min}(\mathrm{~B})$ and at $174^{\circ} \mathrm{C}$ for $10 \mathrm{~min}(\mathrm{C})$.

In the annealing at a temperature below the $T_{\mathrm{s}}$ of the sample $\mathrm{A}$, the endotherm at the lower temperature of the heating curve A shifts to a higher temperature as shown in the heating curve $\mathbf{B}$, while the endotherm at the higher temperature is kept constant. On the other hand, in

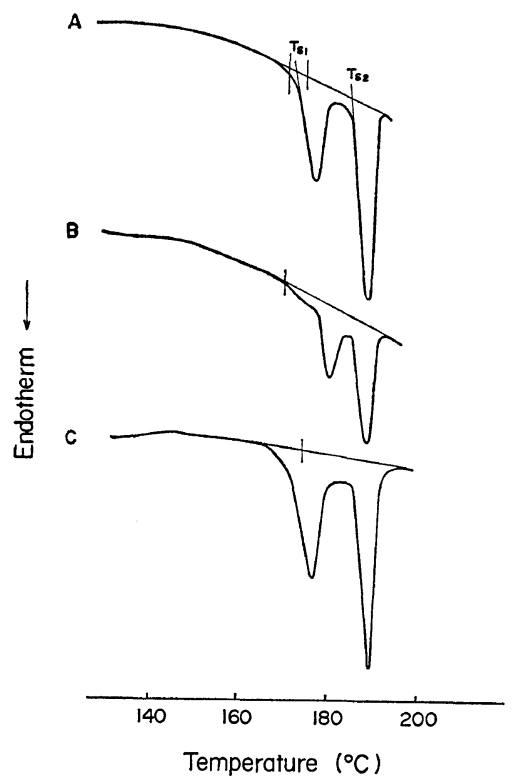

Figure 6. Effect of the annealing temperature on the melting endotherms in the case of the annealing below the starting temperature of the endotherm $\left(T_{\mathrm{s}_{1}}\right)$ : Heating rate, $16^{\circ} \mathrm{C} / \mathrm{min} ; \mathrm{A}$, annealing at $178^{\circ} \mathrm{C}$ for $5 \mathrm{~min}$; $\mathrm{B}$, sample $\mathrm{A}$ annealed again at $170^{\circ} \mathrm{C}$ for $30 \mathrm{~min}$; $\mathrm{C}$, sample $\mathrm{A}$ annealed again at $174^{\circ} \mathrm{C}$ for $10 \mathrm{~min}$; each under a nitrogen atmosphere. the annealing above $T_{\mathrm{s}_{1}}$, the profiles of the heating curve are quite similar to each other (A and $\mathrm{C})$. This fact indicates that the structure corresponding to the endotherm at the lower temperature has a striking resemblance to that of the melt-crystallized material as shown in Figure 5.

Figure 7 shows the heating curves of the sample annealed at $174^{\circ} \mathrm{C}$ for $10 \mathrm{~min}(\mathrm{~A})$, subsequently annealed again at $178^{\circ} \mathrm{C}$ for $15 \mathrm{~min}(\mathrm{~B})$ and annealed thoroughly at $178^{\circ} \mathrm{C}$ for $15 \mathrm{~min}(\mathrm{C})$.

In the annealing of the sample (A) at $178^{\circ} \mathrm{C}$, above $T_{\mathrm{s}_{1}}$ and below $T_{\mathrm{s}_{2}}$, the endotherm at the lower temperature shifts still lower, whereas that at the higher temperature moves even higher (B). The area under the total endotherm remains almost constant. However, the profile of the heating curve $B$ is quite different from that of the heating curve $\mathrm{C}$ - the sample prepared from the as-polymerized material annealed at $178^{\circ} \mathrm{C}$ for $15 \mathrm{~min}$. This fact indicates that the annealing at $174^{\circ} \mathrm{C}$ causes the reorganization of the crystallites and the resulting structure is harder to anneal than that of the as-polymerized.

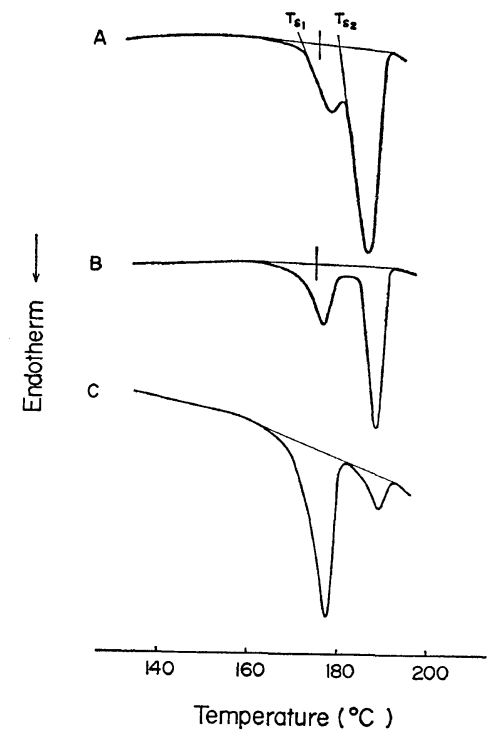

Figure 7. Effect of the annealing temperature on the melting endotherms in relation to $T_{\mathrm{s}}$ : Heating rate, $16^{\circ} \mathrm{C} / \mathrm{min}$; $\mathrm{A}$, annealed at $174^{\circ} \mathrm{C}$ for $10 \mathrm{~min}$; $\mathrm{B}$, sample $\mathrm{A}$ annealed again at $178^{\circ} \mathrm{C}$ for $15 \mathrm{~min}$; $\mathrm{C}$, annealed at $178^{\circ} \mathrm{C}$ for $15 \mathrm{~min}$; each under a nitrogen atmosphere. 
c) Figure 8 shows the heating curves of the melt-crystallized polytetraoxane annealed at various temperatures (the as-polymerized is kept at about $195^{\circ} \mathrm{C}$ for 1 min after melting and cooled with $64^{\circ} \mathrm{C} / \mathrm{min}$ ). The heating curve of the meltcrystallized gives a single endotherm (A). In the annealing at each temperature, a double endotherm is observed in the heating curves. The endotherm at the lower temperature increases and shifts to the higher temperature with increasing annealing temperature, while an endotherm at the higher temperature decreases but shifts to a still higher temperature. An endotherm has been observed in the heating curve of the sample heated up directly without cooling from $170^{\circ} \mathrm{C}\left(T_{\mathrm{s}}+1^{\circ} \mathrm{C}\right)$ which indicates the presence of the crystal in the system during the annealing of the melt-crystallized polytetraoxane. These facts cannot be supposed in the meltcrystallized poly(oxymethylene), acetylated poly-

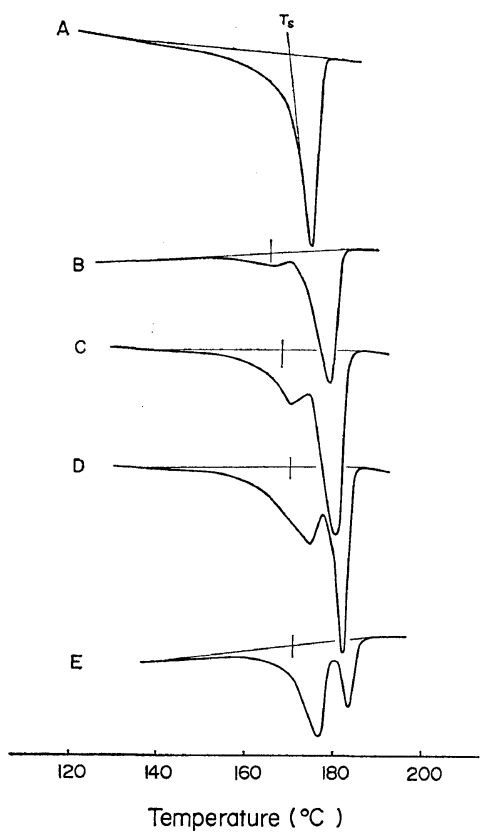

Figure 8. Effect of the annealing temperature on the melting endotherms, in relation to $T_{\mathrm{s}}$ of the melt-crystallized polytetraoxane with the cooling rate of $64^{\circ} \mathrm{C} / \mathrm{min}$ : A, original melt-crystallized; $\mathrm{B}$, sample $\mathrm{A}$ annealed at $165^{\circ} \mathrm{C}\left(T_{\mathrm{s}}-4.0\right) ; \mathrm{C}$, sample A annealed at $168^{\circ} \mathrm{C}\left(T_{\mathrm{S}}-1.0\right)$; $\mathrm{D}$, sample $\mathrm{A}$ annealed at $170^{\circ} \mathrm{C}\left(T_{\mathrm{S}}+1.0\right) ; \mathrm{E}$, annealed at $171^{\circ} \mathrm{C}$; each for $10 \mathrm{~min}$ under a nitrogen atmosphere. trioxane in Figure 5, and in the structure corresponding to the endotherm at lower temperature as shown in Figure 6.

A similar result was reported in the meltcrystallized polyethylene, ${ }^{4}$ where the molecular weight fractionation process occurred during annealing. Accordingly, such a fractionation is assumed in the case of the melt-crystallized polytetraoxane. These phenomena may reflect the structure of the as-polymerized polytetraoxane, namely two kinds of polymer aggregation.

\section{Annealing in a Closed System}

It is convenient to anneal the sample in a glass ampule instead of the system under a nitrogen atmosphere, as is generally done.

Figure 9 shows the melting endotherms of the sample annealed at various temperatures in a glass ampule sealed in air. The profiles of the endotherm ( $\mathrm{A}, \mathrm{B}$, and $\mathrm{C}$ ) are quite similar to.

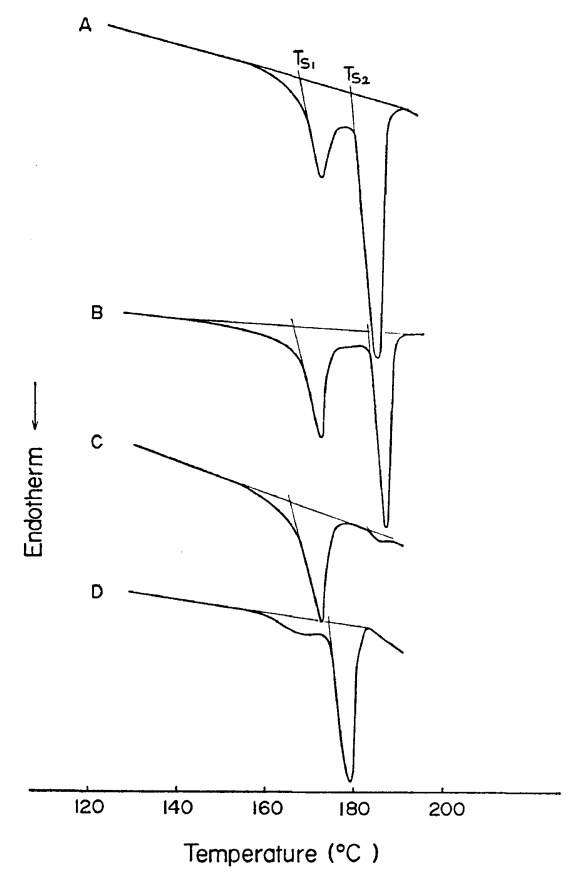

Figure 9. Melting endotherms of polytetraoxane annealed in a closed (A, B, and C) or open (D) ampule at various temperatures for a given time: Polymer yield, $40 \%$ (in air); sample weight, $1.0 \pm$ $0.1 \mathrm{mg}$; heating rate, $16^{\circ} \mathrm{C} / \mathrm{min} ; \mathrm{A}$, annealed at $177^{\circ} \mathrm{C}$ for $5 \mathrm{~min}$; B, annealed at $177^{\circ} \mathrm{C}$ for $30 \mathrm{~min}$; $\mathrm{C}$, annealed at $179^{\circ} \mathrm{C}$ for $10 \mathrm{~min} ; \mathrm{D}$, annealed at $177^{\circ} \mathrm{C}$ for $10 \mathrm{~min}$. 
those annealed at a corresponding temperature in a DSC apparatus under a nitrogen atmosphere.

Oxygen in the closed ampoule may be consumed at the beginning of the annealing and the system is then similar to that under a nitrogen atmosphere. While the heating curve of the sample annealed at $177^{\circ} \mathrm{C}$ in an open ampoule (D) is of a single endothermic peak similar to that annealed under an oxygen atmosphere in Figure 4. Accordingly, the closed ampule can be used for the annealing without oxidation.

Small-and Wide-Angles X-Ray Scattering (SAXS and $W A X S$ )

The same samples as were used in the experiment of Figure 9 were examined by the X-ray diffraction method. The changes of SAXS and WAXS patterns caused by annealing are demonstrated in Figure 10. The feature of SAXS patterns of the annealed sample shows the dis- crete scatterings in the meridional direction indicating the existence of electron density fuctuation (with a long spacing) along the longitudial direction, while all the samples reveal a separated endotherm in the heating curve at the lower temperature in addition to that at the higher -as shown in Figure 9.

When the melting endotherm at the lower temperature increases and that at the higher decreases (as shown in Figure 9), the discrete scatterings become more clear and finally become spot-like corresponding to the long spacing ( $c a$. $170 \AA$ ) of the melt-crystallized material. This fact suggests the realization of the partial melting during annealing and the recrystallization on cooling. The diffuse equatrial scattering decreases with the increase of the melting endotherm at the lower temperature by annealing.

Since it was reported ${ }^{5}$ that the diffuse equa-

SAXS
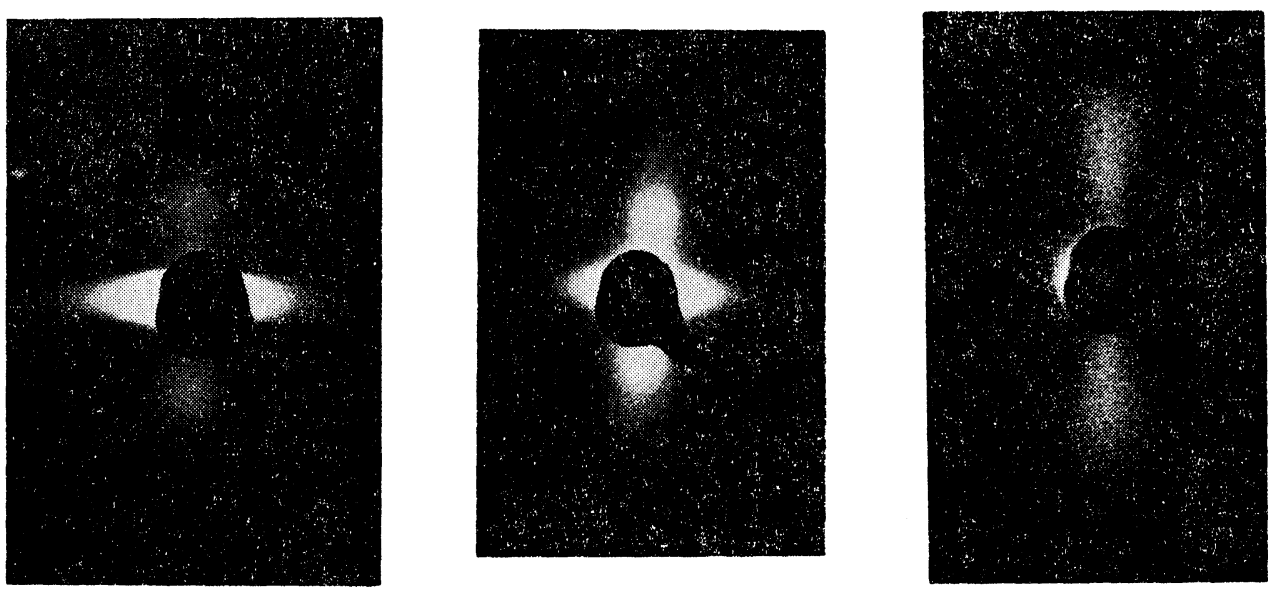

WAXS

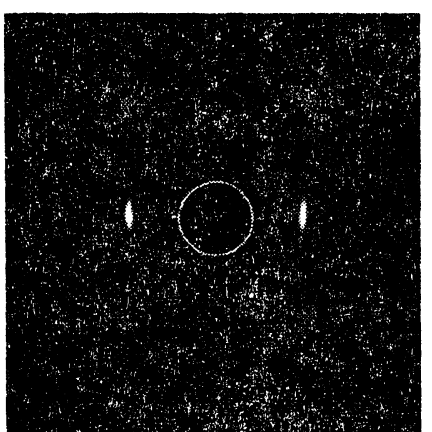

B

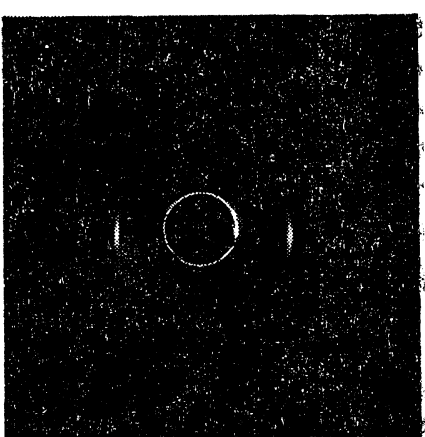

C

Figure 10. Small- and wide-angles $X$-ray scattering patterns of polytetraoxane annealed at various temperatures (the same sample as used in Figure 9): A, annealed at $177^{\circ} \mathrm{C}$ for $5 \mathrm{~min}$; B, annealed at $177^{\circ} \mathrm{C}$ for $30 \mathrm{~min} ; \mathrm{C}$, annealed at $179^{\circ} \mathrm{C}$ for $10 \mathrm{~min}$. 
torial scattering in SAXS is caused by the microvoids between the fibrillar crystals, the lamellar crystal formed from the partial melt may fill up the microvoids, so that the diffuse scattering in the equatorial direction decreases.

The lamellar crystal has a preferential orientation along the fibrillar direction (the $c$-axis of polymer crystal) as indicated by the WAXS patterns in Figure 10. Thus it is assumed that the overgrowth of the folded chain (shish-kebab type) crystal takes place in the formation of the lamellar crystal recrystallized from the partial melt on cooling.

The SAXS photograph of the melt-crystallized polytetraoxane shows only a ring-like diffuse scattering to indicate no preferential orientation of the lamellar crystal formed from the molten phase.

The SAXS intensity diagram of the as-polymerized polytetraoxane obtained by Kratky Uslit camera shows several intensity maxima. Two maxima are rather clear corresponding to the long periods of $c a .100 \AA$ and $c a .450 \AA$, respectively. The intensity maximum corresponding to $c a \cdot 100 \AA$ was suggested already by the SAXS photograph and an electron micrograph. ${ }^{6}$

However, it was observed that the long period of $100 \AA$ increases by annealing at over $140^{\circ} \mathrm{C}$, and abruptly above $165^{\circ} \mathrm{C} .^{7}$ The details for $\mathrm{X}$ ray studies and thermal analyses will be reported soon.

\section{CONCLUSION}

The structure corresponding to the endotherm at the lower temperature on the heating curve of the polytetraoxane annealed above $170^{\circ} \mathrm{C}$ is of the lamellar crystal formed from the partial melt on cooling. This lamellar crystal seems to be of the overgrowth along remaining fibrils (shish-kebab type) to fill up the microvoids presented parallel to the fibrillar axis.
The degradation of polymer occurs during annealing in the presence of oxygen, vigorously in the molten phase, so that the lamellar crystal cannot be formed in the sample annealed under an oxygen atmosphere.

The melt-crystallized form of the original material, as-polymerized polytetraoxane, seems to be easy to fractionate in the annealing process reflecting the fine structure of the as-polymerized product.

The rearrangement of the polymer chain of the as-polymerized material takes place by annealing even above the starting temperature of the melting range $\left(T_{\mathrm{s}}\right)$, so it is assumed that the fine structure of the as-polymerized polytetraoxane is different from the melt-crystallized (the lamellar crystal).

Acknowledgment. The authors are indebted to Mr. T. Ishibashi for the SAXS photographs, to Mr. T. Kato for the preparation of the polytetraoxane crystal and to Mr. O. Yoda for the valuable discussions.

\section{REFERENCES}

1. Y. Nakase, M. Yoshida, A. Ito, and K. Hayashi, J. Polym. Sci., Part A-1, 9, 465 (1971).

2. Y. Nakase and I. Kuriyama, Polymer J., 4, 517 (1973).

3. A. Ito and K. Hayashi, Hydrocarbon Processing, 47, 197 (1968).

4. W. G. Harland, M. M. Khadr, and R. H. Peters, Macromol., 13, 13 (1972).

5. W. O. Statton, J. Polym. Sci., 58, 205 (1962).

6. A. Munoz-Escalona, E. W. Fischer, and G. Wegner, Paper presented at IUPAC Symposium on Macromolecular Chemistry, Budapest, 1969, Vol. 4, p 103.

7. T. Kato, S. Kinoshita, A. Odajima, Y. Nakase, O. Yoda, and I. Kuriyama, presented at the 24th Annual Meeting of the Society of Polymer Science Japan, Tokyo, 1975, p 348. 